\title{
Critical metal signature of sphalerite in Irish-type carbonate-hosted $\mathrm{Zn}-\mathrm{Pb}$ deposits
}

\author{
LinGLi ZHOU ${ }^{1,2}$, STEVEN P. HOLLIS ${ }^{1,2}$, SEAN \\ MCCLENAGHAN $^{3}$, THOMAS RIEGLER ${ }^{3}$, JOHN GUVEN ${ }^{1}$, \\ MURRAY HITZMAN ${ }^{1}$ \\ ${ }^{1}$ iCRAG and School of Earth Sciences, University College \\ Dublin, Belfield, Dublin 4, Ireland, \\ email:lingli.zhou@icrag-centre.org \\ ${ }^{2}$ Geological Survey Ireland, Beggars Bush, Dublin 4, Ireland \\ ${ }^{3}$ Department of Geology, Trinity College Dublin, College \\ Green, Dublin 2, Ireland
}

The Irish Midlands are host to a world-class $\mathrm{Zn}-\mathrm{Pb}$ dsitrict, with over 50 years of exploration that has resulted in the discovery of 5 major deposits (Tynagh, Silvermines, Galmoy, Lisheen and Navan-Tara), and more than 20 deposits. Traditionally, critical metals have not been routinely targeted by exploration; although, analyses have shown Ge to be of interest for trace-elment vectoring. Nevertheless, sphalerite, the chief sulphide mineral in the Irish Midlands, demonstrates a great capability for incorporating a broad range of trace elements, including $\mathrm{Ga}, \mathrm{Ge}$ and $\mathrm{In}$ which may be recovered as smelting by-products. The growing usage of these metals in high-tech applications such as smartphones (Ga, In), fibre-optic cables (Ge) and photovoltaic cells (Ga, $\mathrm{Ge}$, In) has seen a rapid increase in their economic importance as well as supply security-related concerns which are reflected in their critical raw material designation by the European Commission. Despite this, little is known of the critical metal signatures of sphalerite associated with this deposit class. The current study investigates the abundance of $\mathrm{Ga}, \mathrm{Ge}$, In in Irish-type $\mathrm{Zn}-\mathrm{Pb}$ deposits using in-situ laserablation inductively-coupled plasma mass spectrometry (LAICPMS) spot and element mapping techniques on sphalerite from the major mines and deposits across Ireland. Results show that sphalerite is contains anomalous levels of Ge (up to $400 \mathrm{ppm}$ ), with variable Ga concentrations, and insignificant levels of In. Colloform banding of sphalerite significantly effects the distribution of critical metals across sphalerite growths. These trace-element signatures allow us to interpret further the fluid properties and element partitioning behaviour, that account for the enrichment of critical metals in Irish-type carbonate-hosted $\mathrm{Zn}-\mathrm{Pb}$ deposits. 